\title{
CASE OF EXCISION OF THE RIGHT HALF OF THE LARYNX FOR CANCER.
}

\author{
BY ROBER'T H. WOODS, M.B., F.R.C.S.;
}

Throat Surgeon to the Richmond Hospital, Dublin.

[Read in the Surgical Section, December 6, 1895.]

THE interest attaching to radical operation for malignant disease of the throat, and my belief that this is the first case of its kind in Ireland, will, I trust, be deemed sufficient apology for this communication.

J. $M^{\prime} Q$., aged thirty-two, by trade a riveter, came to the throat department of the Richmond Hospital, on March 20th, 1895, complaining of difficulty in swallowing and pain in the throat of six weeks' duration. 'The pain at first was slight, but became progressively worse, and during the last few days was so acute during deglutition, that he voluntarily starved himself rather than endure the agony of swallowing solids; liquids, however, could the taken with comparative ease. He had never previously been ill, and there was no history of syphilis.

His family history was unimportant, except that his father died of cancer of the neck.

On examination, a hard fixed nodule, about the size of a large bean, was seen and felt at the superior border of the right ala of the thyroid cartilage. The laryngoscope showed that, corresponding to this nodule, the larynx contained a large tumour; this tumour involved the right ary-epiglottic fold in its whole extent, touched the posterior pharyngeal wall behind, and so encroached on the lumen of the larynx internally as to diminish the air space by more than half. The larynx was pushed bodily forwards, so that a considerable interval lay between the right arytænoid cartilage and the vertebral column; here there was situated, just above the patent opening of the œsnphagus, a necrotic patch, which lent a gangrenous foetor to the breath, and perhaps caused some of his pain. The glands under the sterno-mastoid muscle at the level of the cricoid cartilage were enlarged. By passing the fore-finger 
of the left hand over the base of the tongue the tumour could be felt to be hard and firm. The lungs were healthy.

The case was diagnosed to be one of cancer, but in order to place the matter beyond doubt, and save the valuable time necessary to differentiate by drugs between it and syphilis, a small piece of the growth was avulsed by means of a sharp hollow forceps, and handed to Dr. H. C. Earl, who submitted it to microscopic examination, and on March 28th reported it to be a carcinoma.

The disease was evidently very far advanced, and must have been established months before it attracted his attention; indeed it is likely that he only suspected mischief when the pain of the ulceration disturbed his quiet.

The question of interference was an anxious one, but, after consultation with my surgical colleagues, it was agreed that it would be better to give him the chance of operation rather than leave him to wait in pain and starvation for inevitable death. "Excision was therefore recommended. The dangers and difficulties of the operation, as well as its after effects and the rarity of permanent cure, were fully and fairly laid before the patient, who, without hesitation, decided on having it performed. He was told that the whole larynx might have to be removed, and he not only agreed to leave the matter entirely in my hands but expressed the wish that I should take away too much rather than too little.

The operation was performed on April 1st. One-sixth of a grain of morphia was injected subcutaneously and the patient chloroformed with a Skinner's inhaler ; a sandbag was placed at the back of the neck and the head extended. Before narcosis was induced he struggled a good deal, and his breathing sounded as if there was some obstruction in the larynx. An incision was carried along the middle line from the hyoid bone to the suprasternal notch, the trachea was bared, and high tracheotomy performed. 
transverse cut was next made from the upper end of the mesial wound outwards, and to the right parallel to the hyoid bone and close below it. The thyroid cartilage was bared and, with the subjacent mucous membrane, cut in the middle line with a stout scissors. The thyrohyoid membrane was similarly treated. The wings of the thyroid cartilage were dilated and the larynx inspected. The growth was confined to the right side and nearly filled the larynx; there was odema of the left ary-epiglottic fold, due apparently to infection from the necrotic surface behind, and explaining the dyspnœa during the early administration of the chloroform. A few drops of a 20 per cent. cocain solution were brushed on the mucous membrane to diminish its sensibility and allow greater freedom of manipulation. A strip of sponge, with string attached, was introduced into the larynx and packed round the upper part of the tracheotomy tube, to which a Trendelenburg's apparatus was attached for the administration of the chloroform during the subsequent. steps of the operation.

The skin and subcutaneous tissues were stripped from the triangle marked by the mesial and horizontal incisions as far back as the sterno-mastoid. The right crico-thyroid membrane and adjacent structures were cut through, the cricoarytænoid joint opened, and the right half of the larynx thus freed from its connections with the cricoid cartilage. The thyrohyoid membrane was next cut close to the hyoid bone, and the epiglottis snipped along the middle line; its right half was brought into the wound and drawn forcibly downwards, while the tissues were cut between the horizontal wound externally and the vallecula within. The great cornu of the hyoid bone was found to run so close to the tumour that it was removed, and the height to which the dissection had to be carried involved, as we afterwards found, division of the hypoglossal nerve; the lingual artery, however, escaped 
The mass was then detached posteriorly from the prevertebral muscles, the bag of the pharynx being divided to the left - the healthy side - of the middle line, the attachments to the carotid sheath were cautiously severed, and finally a pedicle by which it was held to the base of the tongue was snipped through and the mass removed. The hæmorrhage was occasionally pretty sharp, but at each step the bleeding vessels were caught and ligatured; the quantity of blood lost altogether was not great.

Infected glands were then sought for. A number of them were followed towards the angle of the jaw and carefully dissected out. A second chain, underlying the sterno-mastoid at and below the level of the cricoid cartilage, was next isolated and extracted, great care being necessary to avoid wounding the internal jugular vein on which they lay and which they to some extent clothed. The, whole wound was next examined, but nothing suspicious, either to the eye or touch remained. The carotid artery and internal jugular rein were found to have been exposed for three inches of their course.

The raw surfaces were sponged with tr. benzoin co. I am aware that the classical antiseptic and hæmostatic for excision of the larynx is chloride of zinc, but I consider any soluble antiseptic too temporary and unreliable in its action when used in a situation where the secretion cannot fail to carry it away within a very short time. Friar's balsam, on the contrary, forms an adhesive coating to the tissues, and that it effectually prevented infection in this case is sufficiently evidenced by the temperature chart.

The horizontal wound was next sutured, the mesial one was left open; a No. 14 red rubber cesophageal tube was pushed into the stomach and sutured to the skin at the upper end of the central incision. The cavity of the larjnx and lower part of the pharynx were plugged with iodofor ${ }_{1 m}$ 
gauze, and the patient put to bed breathing comfortably through the tracheotomy tube.

The patient took the chloroform badly from first to last. Three times the respiration ceased without mechanical cause, the pulse, which was carefully watched, slowed down, and the patient became pallid and ashy. : Patients after tracheotomy develop a condition of physiological apnoa, the chief cause of which is diminution in the length; and consequently of the capacity, of the passage between the lungs and the outer air. But the condition of the patient on these three occasions was quite different from the apnœa of tracheotomy, as evidenced by the failure of the heart and the change in colour. On each occasion the operation had to be stopped and artificial respiration started. After the third time the chloroform was suspended and the operation finished while the patient lay in a lethargic but not quite unconscious condition. He, however, felt no very acute pain. The tumour was examined microscopically by Dr. Earl and found to be a squamous epithelioma.

During the days immediately following morphia was freely given by the skin, with the double object of lessening the shock and avoiding bronchitis or pneumonia-the conmonest causes of death after this operation. No steam apparatus was used; the temperature of the room was carefully regulated and draughts excluded.

At the end of the first twenty-four hours he had a reactionary temperature of $100.8^{\circ} \mathrm{F}$, and this was the highest point it ever reached. He had no pain, very little tenderness, and had not romited. He was given a little milk through the tube, which he bore well. The wound was dressed, the plug of gauze being removed; and a powder of iodoform and boric acid insufflated before a fresh one was replaced.

Jn the third day the tracheotomy tube was dispensed with; the stitches were taken out of the horizontal wound, 
which had healed by first intention. The stomach tube was removed and cleansed, and the gauze plug withdrawn and not replaced. On the fourth day, his bowels not having been moved since the operation, a saline draught was administered. He shortly afterwards vomited frequently, and complained of an "icy cold pain" in the pit of the stomach. Withdrawal of the stomach tube relieved this pain. The tube was left out, and not re-introduced except at meal times, when it was passed into the osophagus through the wound in the neck.

From this time his recovery was uninterrupted. He was allowed up on the tenth day, and was able to enjoy a pipe on the fourteenth. There was a good deal of secretion from the granulating surface, and saliva trickled into the throat. A convenient apparatus for their removal was made from a bottle with two glass tubes passed through the cork. To one tube an enema syringe was attached "tail on," so that when worked it pumped air from the bottle; and to the other was fixed a rubber tube, to which a long brass nozzle of $\frac{1}{4}$-inch diameter could, if necessary, be fixed. By putting the nozzle to the required spot the secretion and saliva could be removed rapidly by working the syringe, the bottle acting as a reservoir. This little instrument was first designed by me for removing blood and saliva in cleft-palate operations in the "head down" position. I have used it also with very great advantage in laryngofissure and pharyngotomy. By its means blood can be removed in a tenth of the time and with less than a tenth of the trouble taken in sponging, and perhaps, most important of all, without exciting any reflex spasm in the patient.

The patient swallowed corn flour on the twenty-eighth day, and did not require to have the tube passed after that time.

Seven weeks after the operation there was slight inspiratory dyspnœa, due to cicatricial narrowing of the throat. 
This was successfully treated by the daily passage of Schrötter's stenosis tubes.

From this time he was perfectly well. There was absolutely no pain at any time; he slept well, and could swallow meat and drink without difficulty. It was no uncommon thing to see him drink a pint of milk without taking the mug from his mouth. He spoke with a hoarse but very fair voice, making himself heard across an ordinary room without effort. He expressed himself as well pleased with the operation, and said that any inconvenience he had had to suffer was as nothing when compared with the relief it had afforded him. He spent over three weeks at the Convalescent Home, Stillorgan, and was exhibited both at the Surgical Section of the Royal Academy of Medicine and the Laryngological Section of the British Medical Association in London.

$\mathrm{He}$ was examined at regular intervals for any sign of recurrence, with negative results however, until early in August, when an indurated lymphatic gland was felt low down on the right side of the neck, belind the sternal head of the sterno-mastoid muscle. Its nature was only too obvious. Removal was recommended, and agreed to by the patient with a cheerfulness and alacrity that characterised him from the very first, and the operation was undertaken on August 21 st.

In view of the difficulty encountered in keeping him alive under chloroform on the former occasion, it was decided to use cocaïn, and three-quarters of a grain was accordingly injected under the skin through two punctures at the site of incision. The gland was exposed and found lying on the internal jugular vein, just at its junction with the subclavian. The dissection was conducted most cautiously, and the danger of venous canalisation kept in view-an accident once seen by the writer in a fatal case under the hand of the late Professor Billroth. The gland was more than half isolated when a 
membrane was punctured, and air heard to rush through the hole with a characteristic sw - sound. The finger was at once placed on the puncture, and a pause made to watch if any effect followed. There was no change in the patient's condition, so that the quantity of air which had entered the vein must have been too small to cause distress, or else the breach must have been made into the cervical pleura. Either was quite possible in the situation, but the latter was thought more probable. To settle the doubt the patient was directed to cough, During the effort the finger was removed, when a jet of venous blood showed the true state of affairs. An effort was made to secure the puncture, so as to admit of a further attempt to isolate the gland, though the prospect of its possibility was not an encouraging one, it being by this time pretty certain that the gland was adherent to the wall of the vein. The perforation, however, could not be secured, and the attempt was attended by the entry of more air. The patient immediately developed the characteristic symptoms of canalisation. The face became intensely congested, the lips blue, and the skin covered with a profuse sweat. He felt smothered, and asked to be allowed to sit up. This he was let do. Oxygen was procured at once, and administered during inspiration through a tube in the mouth ; the clips were taken from the wound and the edges held firmly together by the fingers, and subsequently clipped by forceps; the wound was then closed and the operation abandoned. The effect of the oxygen was marvellous; the patient's colour at once returned, and his distress ceased. The gas had to be temporarily stopped to allow the apparatus to be adjusted, and he promptly reverted to his former condition, recovering, however, with the re-administration. From its effect on the patient there is little doubt that oxygen is the quickest and best remedy for such cases; and I should recommend that, where there is a risk or certainty of open- 
ing reins near the root of the neck, the operator should have a supply of the gas at hand. After the lapse of threequarters of an hour he had quite recovered, and the oxygen was discontinued. The patient felt quite comfortable that afternoon and the following day, except for some pain in the chest, especially on coughing. He had complained of this, however, before operation.

The cough became more and more distressing, and his condition daily worse, and he died five days later, nearly five months after the excision.

Post-mortem examination.- There was severe inflammation of the whole respiratory tract from the trachea to the bronchioles. The lower lobe of the left lung was of a dusky red colour; and, on squeezing the tissue of the lung, drops of muco-pus exuded on to the cut surface from the air passages. The vein punctured during operation was found to be the internal jugular just as it joined the subclavian The vein was healthy, and no attempt at thrombosis was observable. The site of the first operation in the larynx was perfectly cicatrised, and there was no suspicion of recurrence in loco. There were no mediastinal glands engaged. There is every reason to believe that this gland in which recurrence took place was a far-down member of the chain on the carotid sheath dissected out at the first operation ; and though, as far as one could tell, it was completely excised, it is now evident that the last and minutest link must have been left behind.

It is a rule with some operators not to touch malignant disease of the larynx when there is any palpable glandular enlargement. I question its wisdom. Secondary involvement of the axillary glands does not now-a-days necessarily contra-indicate operation in cancer of the breast, and, though it may add to its difficulty, need not prevent its success; and I can see no reason why, as our technique becomes more 
perfect, the same should not be true of cancer of the larynx. 1 do not regret having acted contrary to this rule. The man's life was prolonged for some months, and his condition from being one of acute suffering and starvation was rendered tolerable and even enjoyable. It is, perhaps, not too much to say that had the patient presented himself a little earlier, before the cancer had progressed quite so far, the same operation might have removed every trace of that most terrible of diseases.

Mr. Croly thought that filling the wound with water was the best way of preventing canalisation. The difficulty of having oxygen always at hand was very much against its use in cases of emergency, such as of air entering a vein. He was rather sceptical as to the value of oxygen in such cases. He (Mr. Croly) desired to put three questions to Mr. Woods:- $-\mathrm{l}$. Why he did not remove the whole larynx? 2. Why he did not use water to prevent canalisation? 3. Why he did not ligate the jugular vein before proceeding to remove the glands adherent to its walls?

Mr. Kendal Franiss said Mr. Woods deserved to be congratulated on having described in a very interesting manner the details of an exceptionally brilliant operation. Unfortunately, the result was fatal, but death could not be ascribed to excision of the larynx : it was due to an extension of the disease, for the removal of which the operation had been undertaken. He believed he was right in describing $\mathrm{Mr}$. Woods' case as the first undertaken in this country for the partial removal of the larynx. He had seen, in such a case, ether administered by the rectum, but the patient died within 48 hours from colliquative diarrhcea, and the post mortem showed acute inflammation of the whole of the large intestine. The administration of chloroform by means of Trendelenburg's apparatus through an opening in the trachea, as performed by Mr. Woods, was far better. He entirely disagreed with $\mathrm{Mr}$. Croly's view that the whole larynx should have been excised. It made a great difference to the patient whether he lost his whole larynx or only hulf. Recurrence did not take place in the healthy side, but in the cicatrix, or in the glands of the neck of the affected side. Moreover, partial excision was far from being as dangerous as complete 
excision. Mr. Franks asked why Mr. Woods, in the second operation, did not tie the vein above and below, and remove the included portion with the adherent implicated glands.

Mr. Wheeler said that the rectal method of administering anæsthetics was not to be recommended. In one case that he had ether thus administered, the intestines became distended, pressed on the diaphragm, and considerably embarrassed breathing.

Professor Bennetr thought that a great source of danger in the administration of ether by the rectum was that the ether was apt to accumulate in the intestines, and therefore the quantity given was not easily controller.

Mr. Woods, in reply to Mr. Croly, said that his finger introduced into the wound completely controlled the vein, and prevented the further entrance of air, and was much more rapidly effectual than filling the wound with water. 'The immediate improvement in the condition of the patient after the administration of oxygen, suggested oxygen as perhaps the best remedy for canalisation. The implicated glands were adherent not only to the internal jugular, but also to the subclavian and innominate veins, and the condition of the patient would not permit of such a serious proceeding as ligature and excision of these veins would involve. 
हैं

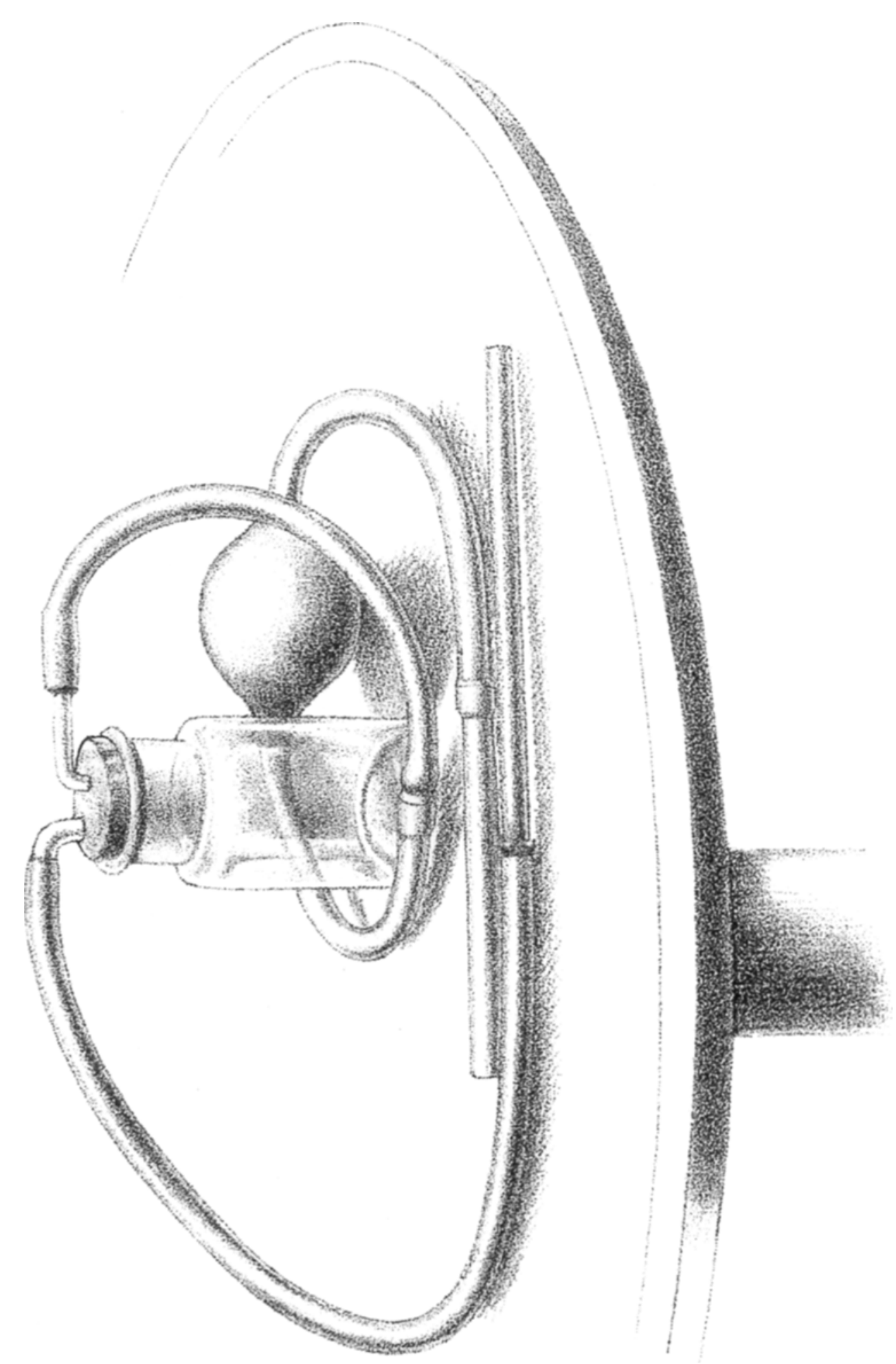

$x$
4
$y$
$u$
$د$
$u$
1
0
0
0
1
0

0

웅

3

I

$\alpha$

$\stackrel{\alpha}{\Sigma}$ 